\title{
Two for one: Coexisting ulcerative colitis and Crohn's disease
}

\author{
Grant I Chen $\mathrm{MD}^{1 *}$, Fred Saibil MD FRCPC ${ }^{2}$, Izabella Morava-Protzner MD PhD FRCPC ${ }^{1}$
}

GI Chen, F Saibil, I Morava-Protzner. Two for one: Coexisting ulcerative colitis and Crohn's disease. Can J Gastroenterol 2002;16(1):29-34.

Three cases of coexisting ulcerative colitis and Crohn's disease are presented. In the first case, the patient had a long-standing history of ulcerative proctitis before developing Crohn's colitis. In the two remaining cases, the patients presented initially with Crohn's disease of the ileum and, subsequent to resection, developed ulcerative colitis. Well-documented cases of patients diagnosed with both ulcerative colitis and Crohn's disease are rare. The literature on such cases is reviewed, and the controversy over whether ulcerative colitis and Crohn's disease are two distinct diseases is explored.

Key Words: Antineutrophil cytoplasmic autoantibodies; antiSaccharomyces cerevisiae mannan antibodies; Crohn's disease; Ulcerative colitis

\section{Doublé : rectocolite hémorragique et maladie de Crohn en concomitance}

\begin{abstract}
RÉSUMÉ : Voici trois cas où se trouvaient en concomitance une rectocolite hémorragique et la maladie de Crohn. Dans le premier, le patient avait des antécédents de longue date de rectite ulcéro-hémorragique avant qu'apparaisse la maladie de Crohn. Dans les deux autres, c'est d'abord une maladie de Crohn de l'iléon qui a été diagnostiquée, puis la rectocolite hémorragique s'est installée à la suite d'une résection de l'intestin. Il existe très peu de cas bien documentés de patients souffrant à la fois d'une rectocolite hémorragique et de la maladie de Crohn. Le présent article passe en revue la documentation sur le sujet et traite de la controverse selon laquelle on se demande si la rectocolite hémorragique et la maladie de Crohn sont deux affections différentes.
\end{abstract}

$\mathrm{C}$ rohn's disease (CD) and ulcerative colitis (UC) are chronic inflammatory bowel diseases (IBDs) of unknown etiologies. The epidemiology, genetics and immunology of both diseases overlap, which can make them difficult to distinguish. Originally, UC and CD were distinguised on the basis of anatomical location. With the widespread acceptance of Crohn's colitis as an entity distinct from ulcerative colitis in the 1950s (1), differentiating the two diseases in cases in which inflammation was confined to the colon became an issue.

Because the cause of these diseases is unknown, these two forms of colitis are distinguished based on a combina- tion of clinical, radiological, endoscopic and pathological characteristics. For many years, the Lennard-Jones classification of IBD provided guidelines that facilitated the separation of UC and CD (2). The recent development of serological testing for perinuclear antineutrophil cytoplasmic autoantibodies (pANCA) and anti-Saccharomyces cerevisiae mannan antibodies (ASCA) has refined our ability to distinguish between the two diseases (3). At a histological level, a further refinement has been proposed $(4,5)$.

Several pathognomonic characteristics of CD allow a definitive diagnosis to be made in many, but not all, patients. These characteristics include perianal disease, small bowel

\footnotetext{
${ }^{1}$ Departments of Medicine and Pathology, and 2Division of Gastroenterology, Sunnybrook and Women's College Health Sciences Centre (Sunnybrook site), University of Toronto, Ontario. *1998 Ilona Diener Clinical Summer Student in IBD

Correspondence and reprints: Dr Fred Saibil, Division of Gastroenterology, Sunnybrook and Women's College Health Sciences Centre

(Sunnybrook site), H-52 2075 Bayview Avenue, Toronto, Ontario M4N 3M5. Telephone 416-480-4727, fax 416-480-5977,

e-mailfred.saibil@utoronto.ca
} 

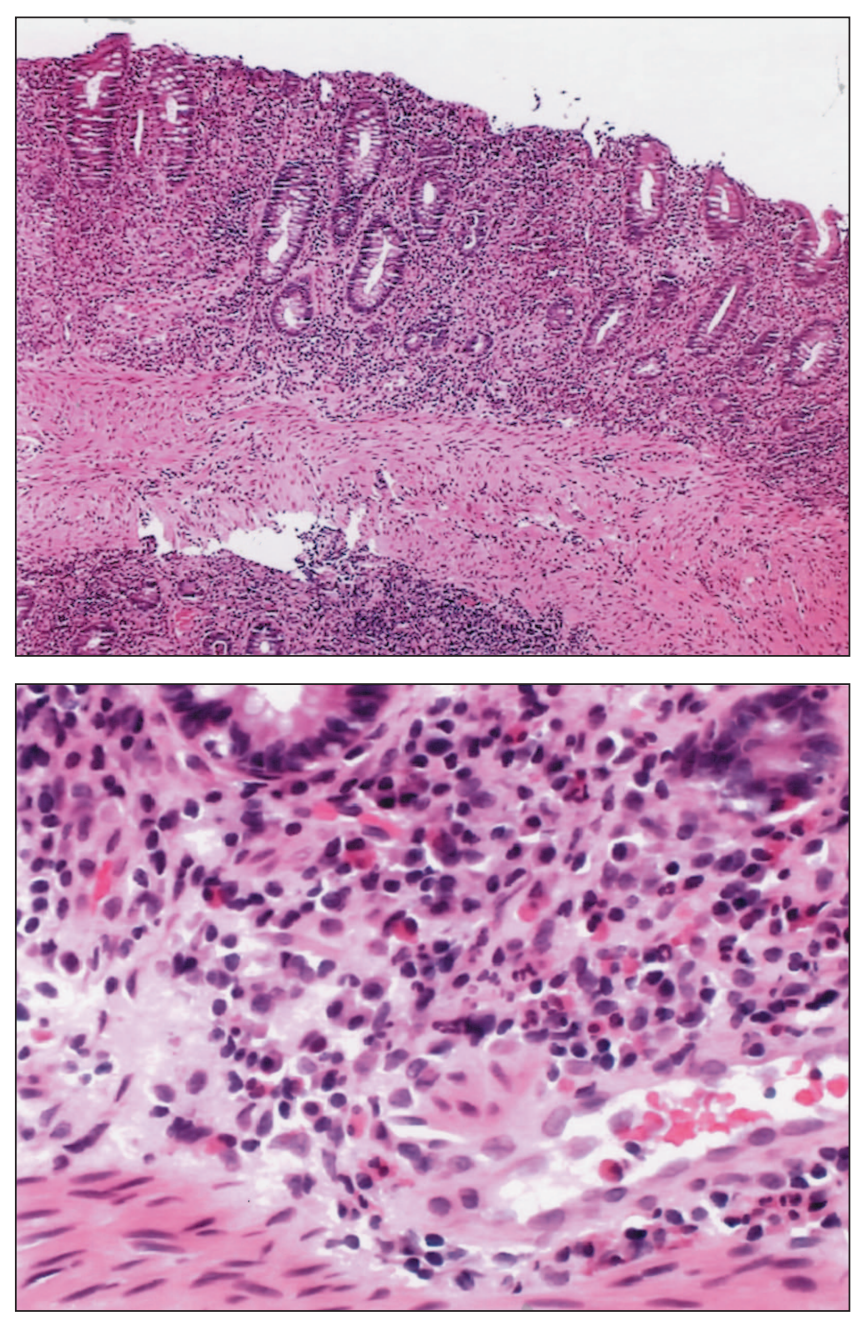

Figure 1) A biopsy specimen from the rectum of case 1 taken in 1981 shows prominent crypt atrophy, severe chronic inflammation (top) and basal plasmacytosis (bottom) consistent with ulcerative colitis. Hematoxylin and eosin stain, original magnification $\times 100$ (top) and $\times 600$ (bottom)

involvement, fistulas, aphthoid erosions, segmental disease, transmural inflammation and granulomas, among others. UC lacks such precise diagnostic features, leaving physicians to rely on certain typical features coupled with an absence of any of the CD-specific identifiers (1). These features include bloody diarrhea and endoscopic findings of rectal disease, including granularity, friability and circumferential inflammation in continuity (in the absence of prior treatment). Histologically, confinement of the process to the mucosa, diffuse mucosal involvement with architectural distortion, and inflammation including basal plasmacytosis and mucus depletion are features that favour a diagnosis of UC. Tanaka's group (4) has suggested that a combination of crypt atrophy and severe chronic inflammation points strongly to UC.

Although UC and CD are presented here as two distinct entities, familial and genetic studies indicate that they are, in fact, interrelated and perhaps even two manifestations of a single basic disease process. A MEDLINE literature review revealed rare instances of well-documented $\mathrm{UC}$ and $\mathrm{CD}$ diagnosed in the same patient. We present three patients in whom both diagnoses were made. The first patient initially presented with UC and subsequently developed coexisting Crohn's colitis. In the other two patients, surgical resection of ileal CD was followed by the development of UC.

\section{CASE PRESENTATIONS}

\section{Case 1}

A 24-year-old man was referred in 1981 for a second opinion with a two-year history of intractable ulcerative proctitis involving the distal 6 to $12 \mathrm{~cm}$ of the rectum. The chief complaint, and only symptom, was rectal bleeding with a normal bowel habit. When he was first seen, he was taking prednisone $20 \mathrm{mg}$ daily, nightly betamethasone enemas (Betnesol, Roberts Pharmaceutical Canada, Inc) and sulfasalazine tablets (Salazopyrin, Pharmacia \& Upjohn Inc, Canada), 1 to $2 \mathrm{~g}$ daily. There was no history of diarrhea, anorexia, weight loss, fever or chills. Past medical history was unremarkable. Family history was significant for two aunts who had an unknown form of 'colitis'. The patient had a Cushingoid appearance, but the physical examination was otherwise normal. Rigid sigmoidoscopy revealed mild but typical UC, limited to the distal $5 \mathrm{~cm}$ of the rectum. A barium enema, including views of the terminal ileum, was normal. A distal rectal biopsy taken at that time demonstrated diffuse mucosal changes, including architectural abnormalities (mainly crypt atrophy) and severe chronic inflammation, with basal plasmacytosis and goblet cell depletion, strongly supporting the diagnosis of UC (Figure 1). Hydrocortisone suppositories (Cortiment Forte, Hoechst Marion Roussel Canada Inc, Canada), $40 \mathrm{mg}$ at bedtime, were substituted for the betamethasone enemas. Sulfasalazine $2 \mathrm{~g}$ daily was continued, and the prednisone was tapered and stopped. There was no change in the bleeding. He was then treated with one sulfasalazine suppository (Salazopyrin, Pharmacia Inc, Sweden) twice daily. Within a few days, the bleeding subsided.

Over the next eight years, he was generally well with occasional episodes of bleeding that resolved with sulfasalazine suppositories. No other treatment was given. Throughout this period, his hemoglobin concentration, white blood cell count, platelet count and erythrocyte sedimentation rate remained normal. In 1989, during a typical exacerbation with daily rectal bleeding, a flexible sigmoidoscopy to $30 \mathrm{~cm}$ revealed moderate ulcerative proctitis in the distal rectum only. He was given 5-aminosalicylate (5-ASA) suppositories (Salofalk, Axcan Pharma Inc, Canada) with no response. He was switched back to the sulfasalazine suppositories and he responded well.

In 1990, 11 years after his initial presentation, he developed painful red nodules on his legs; these were diagnosed as erythema nodosum and treated with a course of prednisone. In August 1991, he presented with three months of nonbloody diarrhea, oral aphthous ulcers, weight loss and abdominal cramps that were generally relieved by bowel movements. There was no urgency or tenesmus. He also experienced an exacerbation of his erythema nodosum. 
Ulceration in the caput of the cecum was seen on colonoscopy; the ileal orifice was obscured by ulceration and edema, and could not be entered. There were serpiginous ulcerations in the region of the hepatic and splenic flexures, and a long segment of continuous disease extending down the descending colon and into the sigmoid. The distal sigmoid and proximal rectum were spared, but there was a distal proctitis, identical with that seen repeatedly since 1981. Crohn's colitis was diagnosed on the basis of the endoscopic findings - segmental disease, skip areas and linear ulcers - and the clinical picture. Symptoms did not improve with oral 5-ASA or metronidazole (Flagyl, RhônePoulenc Rorer Canada Inc) but subsided with prednisone $40 \mathrm{mg}$ daily.

In December 1991, he presented with left mid-abdominal pain radiating to the back and a sore leg with a limp. A positive left psoas sign was found. A computed tomography scan of the abdomen and pelvis illustrated a thickened descending colon wall, a possible fistula into the retroperitoneum and a $1.5 \mathrm{~cm}$ abscess in the left psoas muscle, with a focal enlargement of the left psoas. Rectal and sigmoid thicknesses were normal. He was treated with metronidazole, and the prednisone dose was tapered. He improved somewhat, and ciprofloxacin (Cipro, Bayer Inc, Canada) was added, but there was no further improvement.

In March 1992, he underwent a left hemicolectomy and drainage of the abscess. Examination of the resection specimen showed typical features of Crohn's disease, with a thickened bowel wall, segmental crypt distortion and fullthickness inflammation of the bowel wall, including scattered lymphoid aggregates (Figure 2).

The postoperative course was unremarkable. Five months after surgery, he presented with intermittent rectal bleeding typical of his previous ulcerative proctitis. This was controlled with 5-ASA suppositories. Nine months after surgery, the patient presented with pain and swelling of his left ankle, abdominal pain, decreased appetite, mild weight loss and sores in the mouth. Colonoscopy revealed gross nodularity, mild stricturing and ulceration in two segments of the proximal colon. Although there were no granulomas, both the endoscopic findings and the biopsies were in keeping with recurrent Crohn's colitis. Imaging studies continued to show normal rectal and distal sigmoid wall thicknesses. The patient subsequently sought alternative treatments and was lost to follow-up. At the authors' request, he agreed to provide a blood sample for pANCA and ASCA testing (Prometheus, Inc, USA) (Table 1). At the time of testing, his ulcerative proctitis was clinically quiescent; however, his Crohn's colitis was moderately active.

\section{Case 2}

A 36-year-old man was referred for ongoing management of previously diagnosed IBD. In 1981, at age 21 years, he presented with abdominal cramps and diarrhea; Crohn's ileitis was diagnosed. He was treated medically until 1986, when he was hospitalized with acute right lower quadrant pain
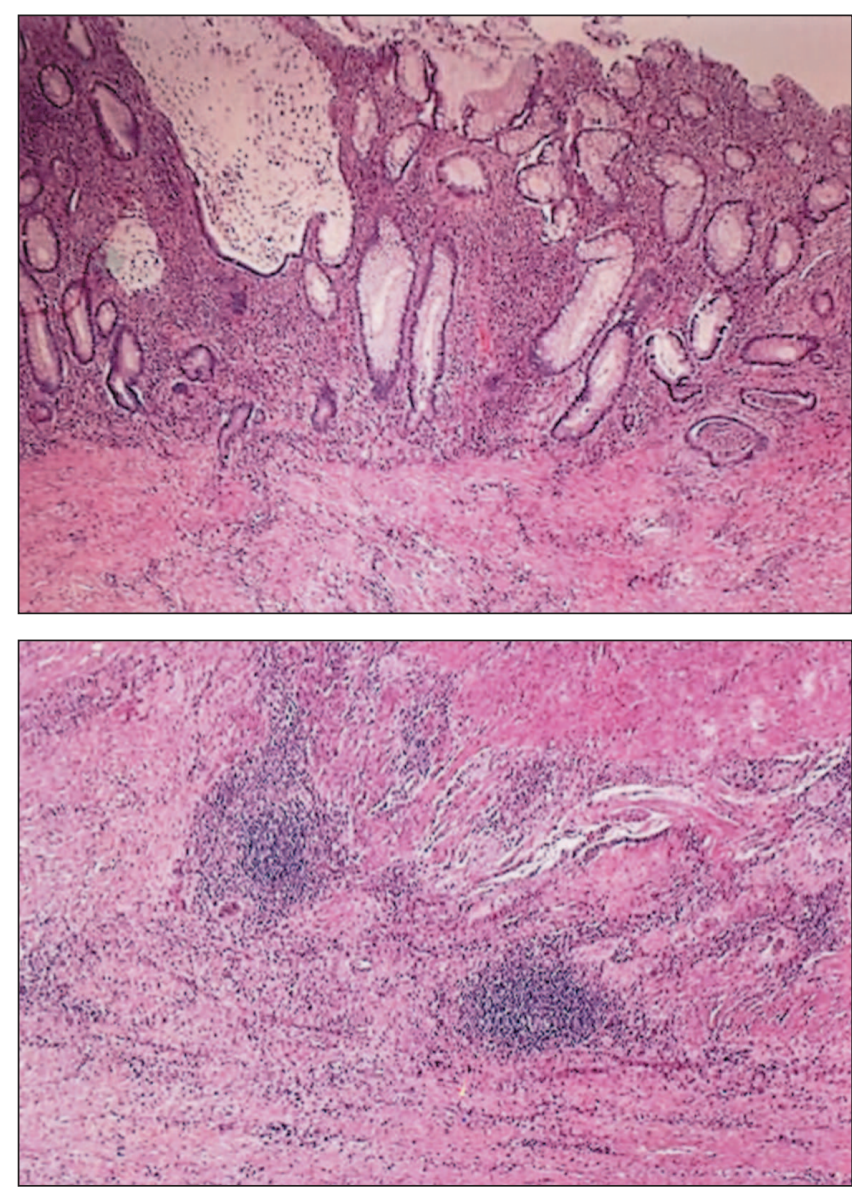

Figure 2) The left hemicolectomy specimen taken in 1992 shows mucosal architectural distortion and full-thickness, chronic inflammation with scattered lymphoid aggregates, consistent with Crohn's disease. Hematoxylin and eosin stain, original magnification $\times 40$

\section{TABLE 1 \\ Results of tests for perinuclear antineutrophil cytoplasmic autoantibodies (pANCA) and anti-Saccharomyces cerevisiae mannan antibodies (ASCA)

\begin{tabular}{lcccc}
\hline & Case 1* $^{*}$ & Case 2 $^{\dagger}$ & Case 3 $^{\ddagger}$ & Reference range \\
\hline ANCA & $<12.1$ & 14.7 & $<12.1$ & $<12.1 \mathrm{EU} / \mathrm{mL}$ \\
ASCA IgA & $<12.5$ & 19.1 & 125.3 & $<20.0 \mathrm{EU} / \mathrm{mL}$ \\
ASCA IgG & 13.5 & 44.0 & 116.4 & $<40 \mathrm{EU} / \mathrm{mL}$
\end{tabular}

All tests were performed by Prometheus, Inc (USA). Prometheus' interpretations of the test results are as follows: ${ }^{*}$ Does not rule out ulcerative colitis (UC) or Crohn's disease (CD): $557 \%$ of patients with this test result combination have $C D$ and $23 \%$ have UC; $¥ 86 \%$ of patients with this test result combination have CD and $11 \%$ have UC. Ig Immunoglobulin; EU Elisa units

that was unresponsive to steroids and signs of peritonitis. Laparotomy revealed free pus and an abscess in the pelvis, approximately $30 \mathrm{~cm}$ of ileitis, and a grossly normal cecum and appendix. An ileocecal resection was performed, with a side-to-side ileocolic anastomosis.

Gross pathological examination revealed typical features of $\mathrm{CD}$, with thickening of the ileum and cecum, and marked narrowing of the ileal lumen. Microscopic features 


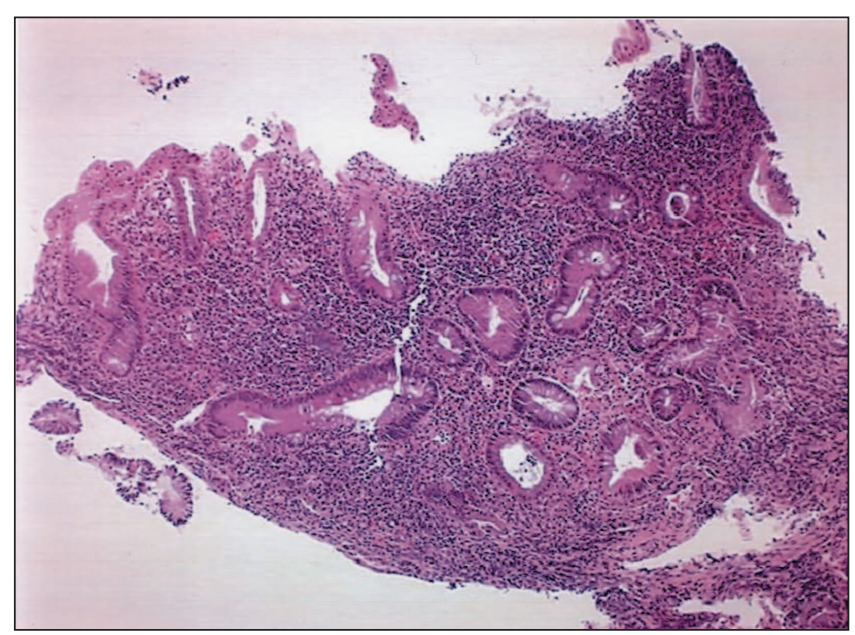

Figure 3) Biopsy specimen from the rectum of case 2 showing mucus depletion, crypt atrophy and distortion, with severe chronic inflammation. Hematoxylin and eosin stain, original magnification $\times 250$

included segmental crypt distortion, transmural granulomatous inflammation with fissure formation, marked submucosal fibrosis, prominent lymphoid aggregates and perforation with abscess formation.

He remained well for seven years and in 1993 presented with bloody diarrhea, false urges and tenesmus. Flexible sigmoidoscopy done elsewhere was said to show typical features of UC to $40 \mathrm{~cm}$ above the anal verge, and normal mucosa beyond. Symptoms were controlled with 5-ASA enemas (Salofalk) and oral 5-ASA (Asacol, Proctor \& Gamble Pharmaceuticals, Canada). He remained on maintenance therapy with oral 5-ASA $1.2 \mathrm{~g}$ twice daily, and 5-ASA suppositories as needed for intermittent urgency.

In 1996, when he was first seen at the authors' institution, the physical examination was normal, except for the surgical scar. Colonoscopy into the neoterminal ileum was normal down to $25 \mathrm{~cm}$; from that point to the anal verge, the typical changes of chronic UC (circumferential, continuous inflammation, with erythema, granularity, friability and complete absence of the vascular pattern) were present. Random biopsies taken from the right colon, transverse colon and left colon at $35 \mathrm{~cm}$ were all normal. Biopsies from the distal $25 \mathrm{~cm}$ were consistent with chronic UC, showing diffuse crypt atrophy and distortion, and severe chronic inflammation with basal plasmacytosis and mucus depletion (Figure 3). During four-and-a-half years of follow-up, the patient remained well, except for one minor flare of his colitis in 1999, which responded promptly to rectal 5-ASA. Tests for pANCA and ASCA (Table 1) were performed in August 2000; at that time, the patient was in remission.

\section{Case 3}

A 28-year-old woman was referred in 1997 for ongoing management of ulcerative proctitis. She had been healthy until 1993, when she was diagnosed with Crohn's ileitis at another institution. She was treated with prednisone; sev- eral months later, she underwent an ileocecal resection for intractable disease. A preoperative colonoscopy revealed a normal colon, except for cecal ulceration and terminal ileitis. The pathology was typical of Crohn's disease, with segmental mucosal architectural distortion, transmural inflammation, fissuring ulcers and granulomas. Postoperative prophylactic therapy was not given.

Six months after the resection, she presented elsewhere with bloody diarrhea, urgency and tenesmus. Colonoscopy was said to have revealed $15 \mathrm{~cm}$ of typical distal ulcerative proctitis. She was treated with 5-ASA enemas (Salofalk enema) and tablets (Pentasa, Hoechst Marion Roussel Canada Inc), with gradual resolution of symptoms. She then experienced similar episodes every four to six months, which were treated with intermittent hydrocortisone foam enemas (Cortifoam, Reed and Carnrick, Canada).

In 1997, when first seen at the authors' institution, she was having five to 10 urgent, bloody bowel motions daily. Her only medications were an oral contraceptive and cod liver oil capsules. Other than the scars of laparoscopic surgery, the physical examination was normal. Flexible sigmoidoscopy to $50 \mathrm{~cm}$ revealed normal mucosa from 50 to $20 \mathrm{~cm}$; from $20 \mathrm{~cm}$ down to the anal verge, the typical changes of acute on chronic UC were present, with confluent erythema, granularity, friability and complete absence of the vascular pattern. The microscopic findings (diffuse crypt atrophy and distortion, severe chronic inflammation with basal plasmacytosis and mucus depletion) were similarly indicative of UC. Clinical remission was achieved with a combination of 5-ASA suppositories (Salofalk), hydrocortisone foam enemas (Cortifoam) and oral 5-ASA (Salofalk) $4 \mathrm{~g}$ daily. In the four years of follow-up since then, there was one minor exacerbation of the colitis in 1999, which responded to 5-ASA suppositories. p-ANCA and ASCA testing were done in July 2000 (Table 1); she was well at that time.

\section{DISCUSSION}

The patient described in case 1 initially presented with distal UC (ulcerative proctitis). After a decade of exacerbations and remissions, he developed a more proximal colitis typical of $\mathrm{CD}$. While no granulomas were ever seen histologically, the clinical and pathological features (see case presentation) of $\mathrm{CD}$ were apparent. The rectal disease remained constant as typical UC (see case presentation), and imaging studies continued to show a normal rectal and distal sigmoid wall thickness. This case represents the extremely rare occurrence of UC and CD simultaneously coexisting in the same patient.

Cases 2 and 3 developed apparent UC following resection of ileal CD. This pattern of sequential coexistence of $\mathrm{CD}$ and UC, while still very uncommon, has been recognized more often.

A MEDLINE literature review contains only six welldocumented cases of coexisting CD and UC (6-11). In three cases, Crohn's ileitis was the initial diagnosis (6-8), and UC developed following resection at varying time 


\section{TABLE 2}

Comparison of cases of coexisting Crohn's disease (CD) and ulcerative colitis (UC)

\begin{tabular}{|c|c|c|c|c|c|}
\hline Sex & $\begin{array}{c}\text { Age at first } \\
\text { diagnosis (years) }\end{array}$ & First diagnosis & $\begin{array}{c}\text { Interval to } \\
\text { second diagnosis }\end{array}$ & Second diagnosis & $\begin{array}{c}\text { Author } \\
\text { (reference) }\end{array}$ \\
\hline Male & 33 & Terminal ileal CD & 4 years & $\begin{array}{l}\text { UC (ileotransverse } \\
\text { anastomosis to rectum) }\end{array}$ & McDermott et al (7) \\
\hline Female & 30 & Ileocolonic CD & 13 months & UC (recto-sigmoid) & White et al (8) \\
\hline Male & 20 & Left-sided UC & 8 years & Terminal ileal CD & Eyeret al (9) \\
\hline Male & 22 & Ulcerative proctitis & 11 years & Crohn's colitis & Chen et $\mathrm{al}^{*}$ \\
\hline Male & 21 & Crohn's ileitis & 12 years & $\begin{array}{c}\text { UC } \\
\text { (sigmoid-rectum) }\end{array}$ & Chen et $\mathrm{al}^{*}$ \\
\hline Female & 24 & Crohn's ileitis & 6 months & $\begin{array}{c}\text { UC } \\
\text { (sigmoid-rectum) }\end{array}$ & Chen et $\mathrm{al}^{*}$ \\
\hline
\end{tabular}

${ }^{*}$ Patients described in the present article

intervals. In the three remaining reports, $\mathrm{UC}$ was the initial diagnosis, and when $\mathrm{CD}$ was subsequently diagnosed, both diseases were thought to be present concurrently $(9,10,11)$. Table 2 summarizes the cases found in the literature and those described in this paper.

In case 1, UC appeared first and CD developed a decade later. Following surgery for the $\mathrm{CD}$, the ulcerative proctitis continued to follow the previous clinical pattern, and the Crohn's colitis recurred nine months after the operation. In cases 2 and 3, the intervals between resection of the CD and subsequent appearance of the UC were seven years and six months, respectively.

A case has been described in which a patient with UC treated with a prolonged course of steroids 'converted' to CD (12). The purpose of that report was to suggest that the two diseases are just parts of a single disease spectrum. We believe that the clinical and pathological evidence in our cases supports the existence of two distinct diseases.

Clinical and pathological features are still the mainstay of both the diagnosis and differentiation of UC and CD, and while tests for pANCA and ASCA are thought to be helpful, the overall utility of these tests in clinical practice has yet to be determined (13-15). Results of the pANCA and ASCA tests in our cases are summarized in Table 1. In case 1 , the results were negative when the patient's recurrent $\mathrm{CD}$ was clinically active. In case 2 , it is difficult to attach any definite significance to the borderline values.

Vasiliauskas et al (16) showed that $100 \%$ of CD patients with a UC-like clinical phenotype are pANCA positive. Case 3 in the present report had the 'typical' serological pattern of CD. She was negative for pANCA, yet she clearly developed a UC-like clinical phenotype. Because $30 \%$ to $40 \%$ of UC patients are pANCA negative, and $100 \%$ of CD patients with UC-like features are pANCA positive, one interpretation is that this patient has both UC and CD.
The controversy over whether UC and CD are one or two separate conditions has been long debated (17-19). Eyer et al (9), using the prevalence rates of UC and CD, calculated that between 15 and 60 patients in the United States have both diseases. This creates a large discrepancy between the number of reported cases and the estimate. Given this situation, previous reporters have argued that this can be explained if the two diseases are distinct entities, because the chance that a patient has two uncommon and distinct diseases at the same time is low $(8,10)$. However, others have argued that this result may be explained if the two diseases are different manifestations of a single disease process and that the clinical presentation and evidence is the result of the individual patient's response to the underlying disease process (7). The situation may be further confounded by the possibility that patients with UC may be genetically predisposed to developing CD and vice versa. Lastly, this may simply be a situation of under-reporting.

The evidence that genetics plays a role in IBD is overwhelming. This evidence comes from studies of families, monozygotic versus dizygotic twins, ethnic groups and genetic markers. First-degree relatives of a proband have a 10- to 15-fold increased risk of developing IBD compared with the general population (20). With the characterization of the human genome, it is expected that significant advances will be achieved soon (21).

Reports of coexisting UC and CD suggest that it is a very rare occurrence. Reaching such a conclusion is difficult because both diagnoses rely on similar clinical, radiological, endoscopic and pathological criteria $(2,22)$. Testing for pANCA and ASCA, and more detailed histological analysis $(4,5)$ allow additional levels of refinement. We have provided evidence for these two separate diagnoses in each of these three patients by combining the Lennard-Jones classification of IBD (2), recent specific histological criteria 
$(4,5)$ and serological testing (3). The paucity of reported cases of co-existing disease compared with the calculations of Eyer et al (9) highlights the controversy over whether $\mathrm{UC}$ and $\mathrm{CD}$ are the same disease or two separate entities. Further genetic studies will hopefully give us more clues and allow us soon to determine the definitive relationship between $\mathrm{CD}$ and UC.

\section{REFERENCES}

1. Kirsner JB. Historical antecedents of inflammatory bowel disease concepts. In: Kirsner JB, Shorter RG, eds. Inflammatory Bowel Disease, 4th edn. Baltimore: Williams \& Wilkins, 1995:7.

2. Lennard-Jones JE. Classification of inflammatory bowel disease. Scand J Gastroenterol Suppl 1989;24:2-6.

3. Targan SR. The utility of ANCA and ASCA in inflammatory bowel disease. Inflamm Bowel Dis 1999;5:61-3.

4. Tanaka M, Riddell RH, Saito H, Soma Y, Hidaka H, Kudo H. Morphologic criteria applicable to biopsy specimens for effective distinction of inflammatory bowel disease from other forms of colitis and of Crohn's disease from ulcerative colitis. Scand J Gastroenterol 1999;34:55-67.

5. Tanaka M, Saito H, Fukuda S, Sasaki Y, Munakata A, Kudo H. Simple mucosal biopsy criteria differentiating among Crohn disease, ulcerative colitis, and other forms of colitis: measurement of validity. Scand J Gastroenterol 2000;35:281-6.

6. Voitk AJ, Owen DR, Lough J. Coexistent regional enteritis and ulcerative colitis. Int Surg 1976;61:535-7.

7. McDermott FT, Pihl EA, Kemp DR, Polglase AL. Coexisting Crohn's disease and ulcerative colitis. Dis Colon Rectum 1982;25:600-2.

8. White CL, Hamilton SR, Diamond MP, Cameron JL. Crohn's disease and ulcerative colitis in the same patient. Gut 1983;24:857-62.

9. Eyer S, Spadaccini C, Walker P, Ansel H, Schwartz M, Sumner HW. Simultaneous ulcerative colitis and Crohn's disease. Am J Gastroenterol 1980;73:345-9.
10. Jones BJM, Gould SR, Pollock DJ. Coexistent ulcerative colitis and Crohn's disease. Postgrad Med J 1985;61:647-9.

11. Mendelsohn RA, Korelitz BI. Crohn's disease presenting as isolated jejunitis years after childhood colitis. Am J Gastroenterol 1993;88:105-8.

12. Dwarakanath AD, Nash J, Rhodes JM. 'Conversion' from ulcerative colitis to Crohn's disease associated with corticosteroid treatment. Gut 1994;35:1141-4.

13. Panaccione R, Sandborn WJ, Colombel J. Is antibody testing for inflammatory bowel disease clinically useful? Gastroenterology 1999;116:1001-3.

14. MacDermott RP. Lack of current clinical value of serological testing in the evaluation of patients with IBD. Inflamm Bowel Dis 1999;5:64-5.

15. Banks PA, Present DH. The role of pANCA and ASCA in differentiating ulcerative colitis, Crohn's disease, and indeterminate colitis. Inflamm Bowel Dis 1999;5:66-7.

16. Vasiliauskas EA, Plevy SE, Landers CJ, et al. Perinuclear antineutrophil cytoplasmic antibodies in patients with Crohn's disease define a clinical subgroup. Gastroenterology 1996;110:1810-9.

17. Shivananda S, Hordijk ML, Pena AS, Mayberry JF. Inflammatory bowel disease: One condition or two? Digestion 1987;38:187-92.

18. Hodgson HJF. One disease or two? In: Allan RN, Keighley MRB, Alexander-Williams J, Hawkins C, eds. Inflammatory Bowel Diseases, 2nd edn. London: Churchill Livingstone, 1990:121-6.

19. Rubin PH, Present DH. Differential diagnosis of chronic ulcerative colitis and Crohn's disease of the colon: One, two, or many diseases? In: Kirsner JB, Shorter RG, eds. Inflammatory Bowel Disease, 4th edn. Baltimore: Williams \& Wilkins, 1995:355-79.

20. Pena AS, Crusius JBA. Genetics of inflammatory bowel disease: Implications for the future. World J Surg 1998;22:390-3.

21. Cho J. Update on inflammatory bowel disease genetics. Curr Gastroenterol Rep 2000;2:434-9.

22. Sartor RB. Pathogenesis and immune mechanisms of chronic inflammatory bowel diseases. Am J Gastroenterol 1997;92(12 Suppl):5S-11S. 


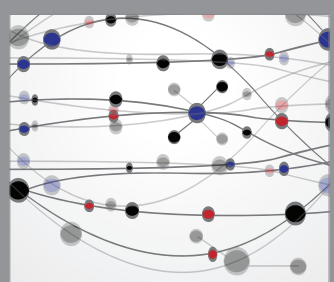

The Scientific World Journal
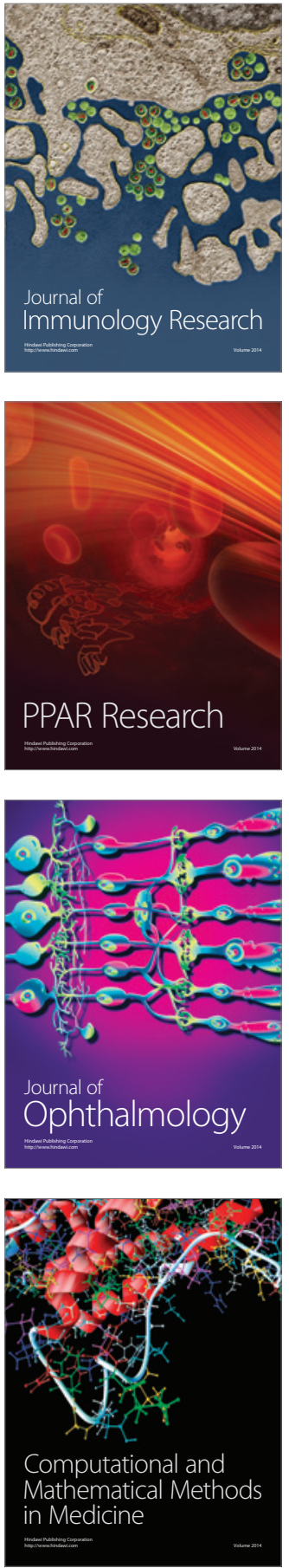

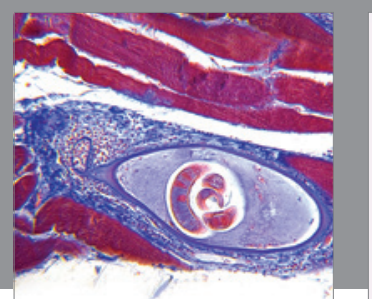

Gastroenterology Research and Practice

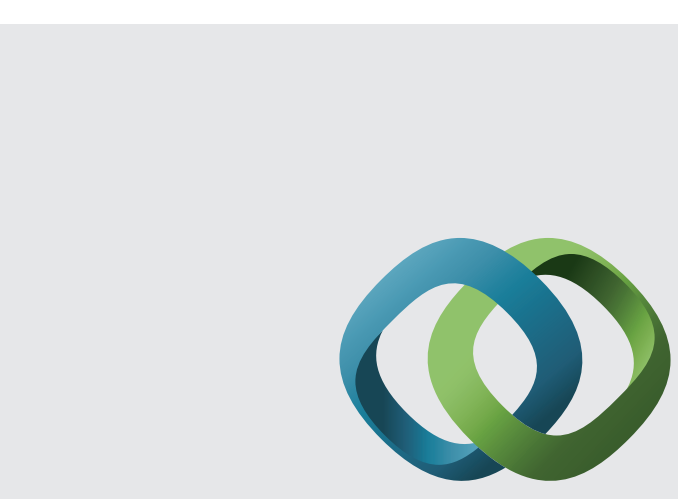

\section{Hindawi}

Submit your manuscripts at

http://www.hindawi.com
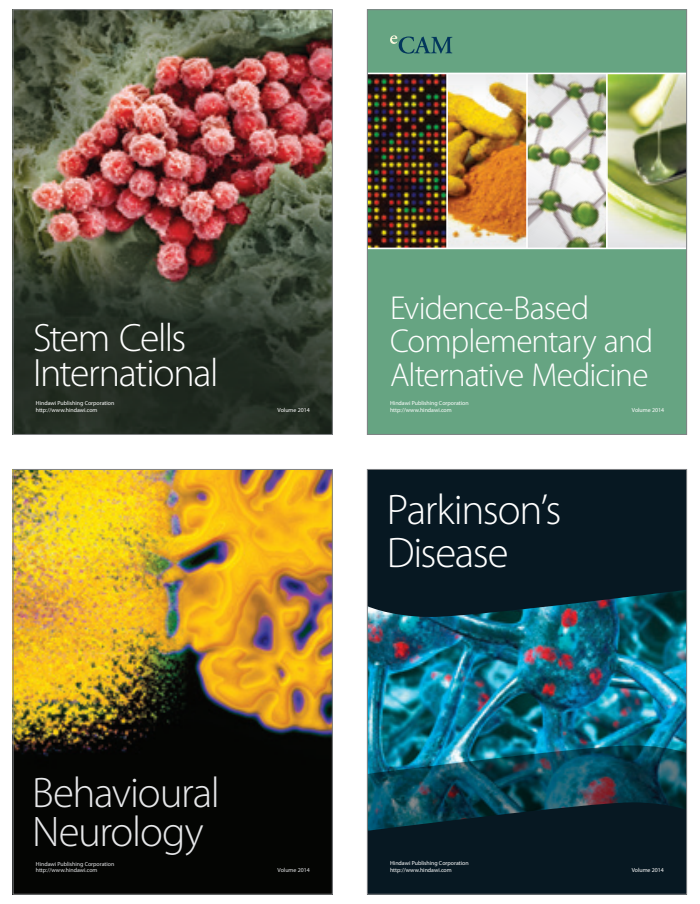
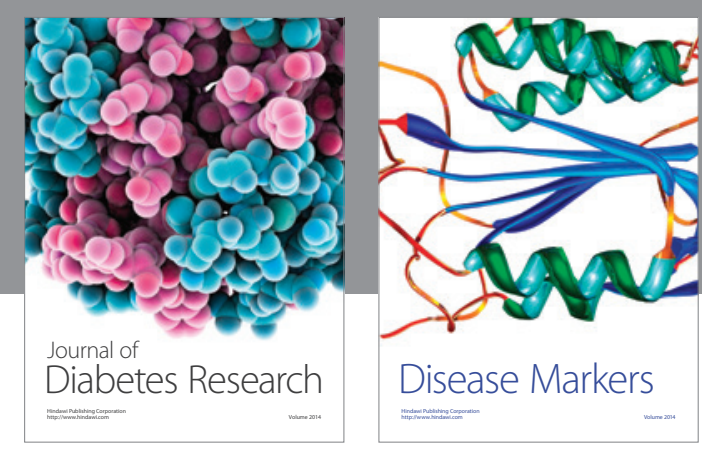

Disease Markers
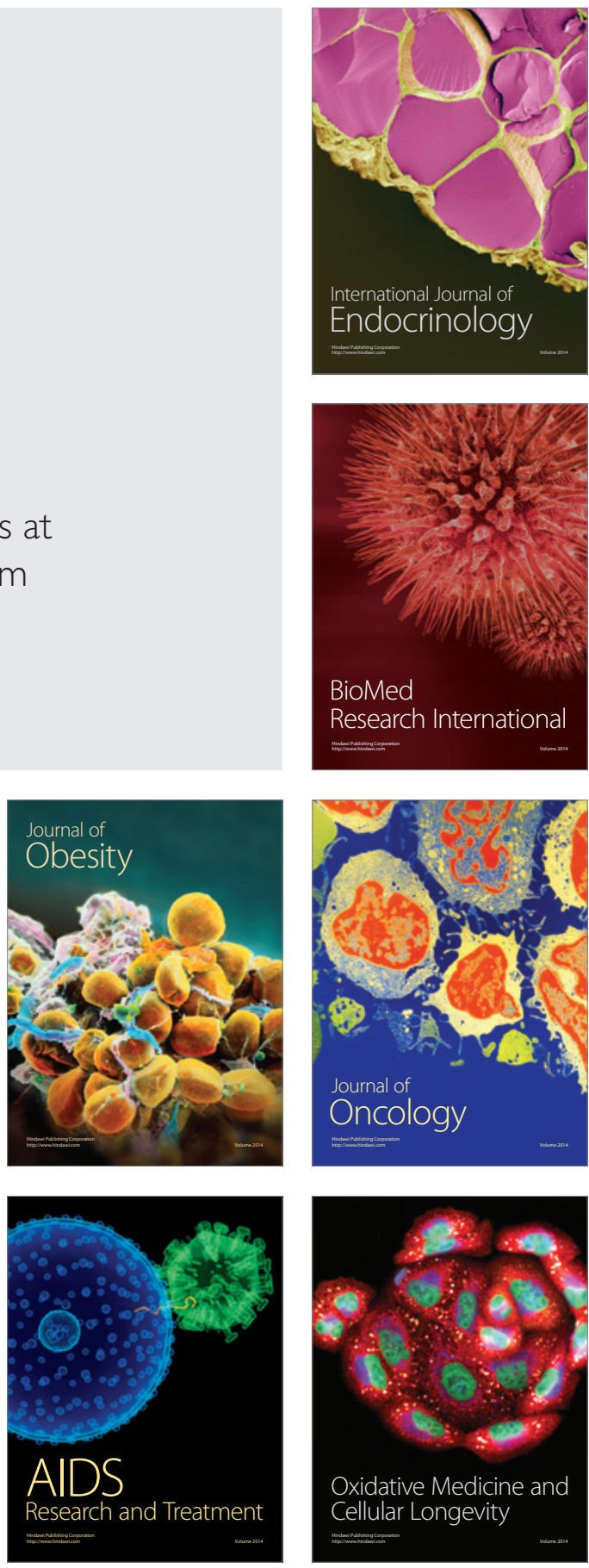